\title{
土木工程建筑施工技术创新探析
}

\author{
黄志强 \\ 新疆维吾尔自治区阿克苏地区住房和城乡建设局，新疆 阿克苏 843000
}

\begin{abstract}
[摘要]近年来, 我国综合国力得到了显著的提升，从而有效的推动了各个行业的稳步健康发展，在这种形势下土木工程行业 要想保证自身稳定持续发展, 那么最为重要的就是需要紧跟社会发展趋势对施工技术进行不断的优化和创新。在社会经济飞 速发展的影响下, 民众的生活水平在不断的提升, 各个行业内的竞争形势越发的激烈, 所以土木工程建筑施工单位需要不断 的增强自身的综合实力, 结合实际情况和需要对施工技术进行完善, 才可以保证在激烈的竞争中长期的保持不败的境地。 [关键词]土木工程; 建筑施工技术; 创新研究
\end{abstract}

DOI： 10.33142/aem.v3i2.3750 中图分类号: TP3;G64 文献标识码: A

\section{Analysis on the Innovation of Civil Engineering Construction Technology}

HUANG Zhiqiang

Xinjiang Aksu Housing and Urban Rural Development Bureau, Aksu, Xinjiang, 843000, China

\begin{abstract}
In recent years, Chinese comprehensive national strength has been significantly improved, which effectively promotes the steady and healthy development of various industries. In this situation, if the civil engineering industry wants to ensure its stable and sustainable development, then the most important thing is to keep up with the social development trend and constantly optimize and innovate the construction technology. Under the influence of the rapid development of social economy, people's living standards are constantly improving and the competition in various industries is more and more fierce, so civil engineering construction units need to constantly enhance their comprehensive strength and combine with the actual situation and need to improve the construction technology, so as to ensure the long-term invincible situation in the fierce competition.
\end{abstract}

Keywords: civil engineering; construction technology; innovation research

\section{引言}

在社会快速发展的推动下, 人们对土木工程提出了更高的要求, 为了满足人们对土木工程的需要, 土木工程施工 技术在不断的进行创新。就以往土木工程施工技术以及施工方法实际情况来看, 很显然已经无法再满足工程施工建造 的实际需要了, 所以我们应当综合各方面实际情况和需要来不断的推进施工技术的研究和创新工作。

\section{1 土木工程建筑施工内容及其特点}

首先, 针对土木工程施工技术加以创新可以有效的为土木工程施工质量和施工效率的提升给予保障, 增强施工单 位的综合实力。其次，对施工技术进行创新和改革可以切实的缩减整个土木工程的成本，提升资金的利用效率，促进 工程项目收益的提高。再有，也可以切实的缓解当前土木工程施工中涉及到的各项问题以及危险隐患，从而为社会和 谐稳定发展打下良好的基础。首先, 针对土木工程施工建造过程中所需要使用到的各项施工技术进行严格的把控, 保 证施工技术按照规范要求加以运用, 从而切实的促进工程施工质量的提高。现如今在土木工程行业内, 人们对于施工 技术创新工作给予了更多的关注，从而有效的促进了整个土木工程行业的良好发展 ${ }^{[1]}$ 。其次，在实际组织实施工程建设 工作的时候, 针对施工技术进行创新也可以切实的解决工程建设中所存在的诸多隐患, 从而切实的提升工程施工建造 的安全性, 提升资源利用效率 ${ }^{[2]}$ 。

\section{2 土木工程施工技术创新中存在的问题}

因为在组织开展土木工程施工建造工作的时候, 施工人员对于施工技术缺少正确的认知, 这样就会造成将施工技术 加以实践运用的时候, 会对施工质量造成巨大的影响, 所以需要施工工作人员具备良好的思维能力。当下, 我国土木建 筑工程施工技术整体水平还没有达到成熟的状态, 所以其还存在巨大的发展空间, 需要相关研究人员在实际工作中充分 结合实际情况和需要来落实施工技术创新工作。就土木工程施工中各方面的实际情况来说, 土木工程施工技术具有较强 的复杂性和多变性, 为了切实的保证各项施工工作的质量和效果, 需要在充分结合各方面实际情况的基础上制定完善的施工 计划以及针对性的应急措施 ${ }^{[3]}$ 。换句话来说也就是在正式开始施工工作的初期, 施工管理工作人员应当切实的做好施工现场 的实地勘察工作, 对工程所处地区各方面情况进行全面的了解。结合勘察结果来制定完善的施工方案, 并且对于施工过程中 可能遇到的各种问题进行预判, 制定针对性的预防和解决方案, 从而为后续各项施工工作的有序高效的开展创造良好的基础。 


\section{3 土木工程建筑施工技术创新}

\section{1 预应力技术创新}

切实的针对土木工程建筑施工技术进行优化和创新, 首先需要针对预应力加以创新, 在整个过程中需要重视的是 体外预应力的发展以及实际运用, 体外预应力也就是将语音里设置在混凝土截面外部, 与以往结构部件的设置相对比 来说, 可以与预应力筋进行连接。实施这项技术的创新能够将体外预应力高效的运用到相关特殊结构以及混凝土道桥 工程施工建造之中。粘结体外预应力是工作的主要表现特征, 这种预应力对于管道工程后续维保和管理工作的实施能 够起到一定的辅助作用, 在整个施工过程中需要施工工作人员对施工技术进行全面的把控。无粘结力体外预应力系统 是当前使用最为频繁的一种施工方式, 不但可以对预应力技术加以创新, 并且还可以提升预应力结构的设计效果, 结 合各方面实际情况来说, 提升预应力的使用效果, 在实际施工过程中应当切实的对预应力在极限状态下实际情况加以 综合分析研究, 这样才能保证预应力具有良好的实用性 ${ }^{[4]}$ 。

\section{2 土木工程建筑中的新型深基坑施工技术}

(1) 桩针支持系统。通常来说桩针固定系统往往都是被运用在地质结构较差或者是规模较大的工程建造中。其次, 套管水冲法成锚技术的作用也是非常重要的, 这项技术的适用范围较为广泛, 其适合被使用在各种环境中, 但是使用 效率和效果还有巨大的发展空间。(2) 支挡和支重结构的一体化。这项技术通常都是被人们运用在进行底下支撑结构 的建造或者是加固桩建造之中, 也可以当作是永久性的支护结构。这项技术的使用不但可以提升基坑结构的载荷能力, 并且也可以促进各项施工工作的有序高效开展。(3) 钻孔桩的施工技术中的旋转挖掘过程。在旋转挖掘施工方法不断 发展的影响下, 经过大量的实践分析研究我们发现, 这项技术的运用可以切实的规避因为人为因素而造成的诸多施工 事故的发生，不但能够切实的对施工质量加以保证，也可以促进施工效率的提升 ${ }^{[5]}$ 。

\section{3 地基土方旋挖施工技术的创新}

就那些高层土木工程项目施工情况来说, 对于地基结构的施工要求相对较高, 在实施低级挖掘以及建筑工程施工 建造工作的视乎, 旋挖施工方法使用较为频繁, 这种方法的运用可以增强高层建筑地基结构的整体稳定性。这种施工 方式也可以缓解人工钻孔施工造成的工程质量问题，运用这种施工方法也可以有效的促进钻孔施工工作的效率的提升。 钻孔灌注桩施工技术是当前使用最为频繁的一种土木工程施工技术, 要想切实的对旋挖施工效果加以保证, 还需要针 对旋挖施工技术以及施工设备进行切实的优化和创新，从而促进土木工程施工技术整体水平的不断提高。

\section{4 完善土木工程建筑施工技术创新体系}

在社会快速发展的影响下, 我国土木工程行业得到了良好的进步发展, 与此同时土工工程施工技术中所存在的诸 多问题越发的凸现出来, 要想切实的对这些问题加以合理地解决, 那么还需要对土木工建筑施工技术进行切实的优化 创新, 保证施工技术能够具备良好的实用性, 为工程施工质量的不断提高也起到良好的辅助作用。针对具有一定特殊 性的施工技术加以深入的分析研究, 确保技术能够满足工程建造实际需要。在当前市场经济环境下, 施工技术也需要 紧跟社会发展形势不断的提升整体水平, 但是现实情况来说, 施工人员专业素质较差, 所以还需要利用有效的方式方 法来加以提升。土木工程施工企业应当加大力度聘任专业人才, 并且制定专业人员培训方案, 不断的提升工作人员的 专业水平。再有, 企业还应当结合自身实际情况和需要来制定专门的奖惩机制, 从而不断提升施工人员的工作积极性。

\section{5 设备更新发展趋势}

还有就是对于土木工程建筑施工中的一些科技设计的更科学了。像数控的钢筋䈐机就是由工业计算机精确的控制 弯曲程度来代替人工弯曲的, 主要对于棒材钢筋的加工, 这种新技术的产生可以一次性代替 20 个 30个人工的力量。 这种设备可以一次性弯曲很多根钢筋, 既可以同时运作, 也可以单独运作, 这种设施的发明对于土木工程建筑施工技 术来说, 无疑是一项很省人力的科技。

\section{4 结束语}

总的来说, 当前建筑工程施工单位加大了建筑施工技术的创新研究力度, 有效的促进了建筑施工单位的综合实力 的发展。在当前快速发展的经济环境中, 土木工程建筑增强了对建筑施工技术的研究, 从而切实的对土木工程建设中 各种问题进行了解决, 要想保证土木工程施工技术的优化和创新, 就应当从各个细节入手, 这样才能不断的提升土木 工程施工技术整体水平，带动整个行业的持续健康发展。

\section{[参考文献]}

[1]杨会东. 土木工程建筑施工技术及创新的研究 [J]. 居舍, 2021 (7) : 162-163.

[2]顾宇.土木工程建筑施工技术创新探究 [J]. 黑龙江科学, 2021, 12 (4): 150-151.

[3]张亚斌. 土木工程建筑施工技术创新研究 [J]. 居业, 2020(12): 85-86.

[4]蒲东才.土木工程建筑施工技术创新研究 [J]. 四川水泥, 2020 (11) : 224-225.

[5]罗庆华.土木工程建筑施工技术及创新方式 $[J]$. 房地产世界, 2020(20): 79-81.

作者简介: 黄志强 (1963.12-), 毕业于: 新疆农业大学, 专业: 水利系, 当前就职于: 新疆维吾尔自治区阿克苏地区 住房和城乡建设局, 职称级别: 副高 5 级。 